\title{
Pelatihan Penggunaan Market Place sebagai Media Pemasaran Online di Paguyuban Tanaman Hias Desa Ciberem untuk Memperluas Pemasaran di Era Pandemi
}

\author{
Dinar Mustofa ${ }^{1}$, Yusmedi Nurfaizal ${ }^{2}$, Dola Innolda ${ }^{3}$, Nadilla Al Azhar ${ }^{4}$ \\ 1,2,3,4 Universitas Amikom Purwokerto \\ Jl. Letjend Pol. Soemarto, Watumas, Purwanegara, Kec. Purwokerto Utara, Kab. Banyumas, \\ Indonesia \\ e-mail: ${ }^{1}$ dinar.mustofa@amikompurwokerto.ac.id, ${ }^{2}$ faizal@amikompurwokerto.ac.id, \\ 32dinnoolda@gmail.com, ${ }^{4}$ nadillaala@gmail.com
}

\begin{abstract}
Abstrak
Masa pandemi yang disebabkan oleh Covid 19 saat ini merupakan masalah yang sangat berat yang dihadapi oleh para pelaku bisnis. Hampir semua lapisan masyarakat terkena dampaknya hingga sangat mempengaruhi kondisi ekonomi semua orang. Para pelaku bisnis tanaman hias di wilayah desa ciberem kabupaten Banyumas mengalami penurunan omset hingga 90\% karena keterbatasan tempat penjualan. Solusi untuk saat ini adalah memperluas pemasaran yang mengurangi kontak langsung dan menghindari keramaian. Penjualan melalui market place merupakan terobosan yang dirasa tepat untuk mendongkrak penjualan tanaman hias. Dengan memanfaatkan market place, para pengusaha tanaman hias dapat memasarkan produk tanaman hias tidak hanya di dalam area banyumas saja, tetapi bisa memperluas mangsa pasar ke seluruh indonesia, bahkan luar negeri. Kegiatan pengabdian ini dilaksanakan untuk memberikan pembelajaran dan keterampilan kepada paguyuban tanaman hias di desa ciberem tentang pemanfaatan media market place sebagai sarana untuk penjualan dan promosi yang efektif dan efisien untuk bertahan di era pandemi. Metode yang digunakan dalam kegiatan pengabdian di desa ciberem ini adalah pengumpulan data dan pendekatan persuasif edukatif yang mana nantinya akan dilanjutkan dengan mempraktekan langsung hasil dari pelatihan. Harapannya kegiatan ini dapat membantu para pelaku bisnis tanaman hias untuk membuat toko online di beberapa marketplace sehingga penjualan tanaman hias dapat meningkat dan memperluas area pemasaran tanpa mengeluarkan budget lebih untuk biaya promosi.
\end{abstract}

Kata Kunci: Marketplace, Pandemi, Pemasaran Online

\section{Abstract}

The current pandemic period caused by Covid 19 is a very serious problem faced by business people. Almost all walks of life are affected by the impact which greatly affects the economic condition of everyone. The ornamental plant business in the village area of Ciberem, Banyumas district has experienced a decrease in turnover of up to $90 \%$ due to limited sales places. The solution for now is to expand marketing which reduces direct contact and avoids crowds. Selling through the market place is a breakthrough that is considered appropriate to boost sales of ornamental plants. By utilizing the market place, ornamental plant entrepreneurs can market ornamental plant products not only in the Banyumas area, but can expand market prey throughout Indonesia, even abroad. This service activity is carried out to provide learning and skills to the ornamental plant association in Ciberem village regarding the use of the media market place as a means for effective and efficient sales and promotion to survive in the 
pandemic era. The method used in community service activities in Ciberem village is data collection and a persuasive, educative approach which will be continued by directly practicing the results of the training. It is hoped that this activity can help ornamental plant business people to create online shops in several marketplaces so that sales of ornamental plants can increase and expand the marketing area without spending more budget for promotional cost. Keywords: Market Place, Pandemic, Online Marketing

\section{Pendahuluan}

Desa Ciberem merupakan salah satu desa yang terletak di kecamatan sumbang, kabupaten Banyumas, Jawa Tengah. Dengan kondisi geografis yang memiliki curah hujan lebih tinggi dibandingkan wilayah lain di kabupaten banyumas, membuat struktur tanah di kawasan desa ciberem menjadi subur, sehinga tanahnya cocok sebagai media tanam untuk tanaman hias. Mayoritas masyarakat disana memanfaatkan lahan mereka untuk budidaya tanaman hias, sehingga sumber perekonomian masyarakat desa ciberem adalah sebagai petani tanaman hias. Paguyuban tanaman hias desa ciberem merupakan kumpulan dari UMKM peserta program PKBM yang berhasil menjadi bisnis yang dapat bertahan hingga saat ini, bahkan diera pandemi. Meskipun bisa bertahan, sejak adanya covid 19 omset penjualan mengalami penurunan hingga $90 \%$. Penurunan terjadi karena sepinya pengunjung di tempat - tempat wisata sekitar banyumas yang tadinya digunakan sebagai area untuk berjualan oleh para pelaku usaha tanaman hias.

Digital Marketing merupakan salah satu usaha untuk memasarkan atau mempromosikan sebuah produk melalui media internet agar bisa menjangkau konsumen maupun calon konsumen dengan cepat (Hendriadi, Sari and Padilah, 2019). Salah satu jenis Digital Marketing yang dimanfaatkan oleh kebanyakan pelaku UMKM adalah Market Place. Market Place memiliki konsep seperti pasar tradisional yang seakan akan berada di internet, pemilik memiliki peran sebagai pihak yang mempertemukan antara penjual dan pembeli melalui media seperti website ataupun aplikasi (Artaya and Purworusmiardi, 2019). Menurut (nathasya 2018), Marketplace didefinisikan sebagai website atau aplikasi online yang memfasilitasi proses jual beli dari berbagai toko.

Marketplace adalah sebuah pasar elektronik yang melakukan kegiatan menjual dan membeli suatu barang ataupun jasa yang meliputi 3 Aspek (b2b, b2c \& c2c) dimana B2B (Bisnis to Bisnis) mendominasi sampai $75 \%$ di marketplace. Marketplace merupakan puncak dari ecommerce, marketplace biasanya mempunyai sistem tersendiri yang dapat mengatur ratusan bahkan jutaan produk yang ingin dijual maupun di beli contohnya : eBay.com, bukalapak.com, Xohop.com, di dalam marketplace terdapat Toko Online adalah sebuah tempat yang berupa Website yang didalamnya terdapat program e-commerce yaitu cart dimana pembeli tidak harus menghubungi pemilik toko tersebut terlebih dahulu seperti : Lazada, Berniaga.com, Xohop.com Merchant. Contoh dari marketplace mulai dari yang paling sederhana adalah FJB Kaskus, Craiglist \& OLX (Xohop 2017).

Menurut (Artaya and Purworusmiardi, 2019), Di indonesia ada beberapa marketplace yang bisa dikategorikan menjadi jenis industri besar dan memang sudah dikenal dikalangan masyarakat. Berikut adalah contoh beberapa parket place di indonesia yang namanya sudah terkenal :

1. Tokopedia, Tokopedia adalah online marketplace terbesar di Indonesia. Bagi yang tertarik untuk membuka toko sendiri, tentu bisa melakukannya dengan mudah di 
Tokopedia. Marketplace ini sudah sedemikian familier di mata konsumen tanah air dan sudah dikenal cukup lama sampai saat ini, banyak digunakan oleh pelaku usaha di Indonesia dalam upaya memasarkan dan menjual termasuk mendistribusikan produk andalam mereka. Tokopedia sudah mendapatkan funding sampai dengan series G. Pada November 2018 kemarin, mereka mendapatkan funding dari Softbank Vision Fund.

2. Bukalapak, masyarakat Indonesia pasti tidak asing dengan nama Bukalapak. Sebagai salah satu online marketplace ternama di Indonesia, Bukalapak juga menyediakan tempat bagi pelaku usaha yang tertarik berjualan secara online atau daring. Bukalapak mengutamakan kemudahan dan keandalan platformnya agar pengguna bisa mendapatkan user experience yang terbaik. Kontribusi Bukalapak dalam menunjang pertumbuhan kegiatan belanja secara online demikian besar bagi pelaku usaha yang ingin menjual produk unggulannya secara online.

3. BliBli, merupakan pusat belanja online dengan beragam produk dari komputer dan gadget, fashion, kesehatan dan kecantikan, ibu dan anak, rumah dan dekorasi, otomotif. Blibli juga memberikan berbagai promosi khusus, tiket dan voucher untuk pengunjung dan pelanggan. Pertumbuhan BliBli sebagai salah satu marketplace di Indonesia memiliki determinasi cukup besar bagi mobilitas belanja secara online bagi konsumen dalam negeri.

4. JD.ID, adalah sebuah department store online yang memiliki variasi barang yang cukup luas. Konsumen bisa menemukan berbagai kategori produk seperti fashion, elektronik, dan gadget. JD.ID diluncurkan pada November 2015 dan merupakan anak perusahaan e-commerce dari China JD.com.

5. Shopee, adalah salah satu pemain penting di Indonesia, terutama di negara "mobilefirst" Shopee adalah online marketplace terdiversifikasi dan terdepan yang juga menyediakan pengalaman belanja web biasa. Platform belanja online yang satu ini tersedia di seluruh Asia Tenggara, Shopee juga ada di Singapura, Filipina, Malaysia, Thailand, Vietnam, serta di Taiwan.

6. Elevenia, Elevenia memiliki lebih dari 30.000 penjual dan lebih dari 4 juta produk dari beragam kategori, seperti peralatan rumah tangga, keluarga, kesehatan, kecantikan dan fashion, komputer dan gadget, peralatan olahraga, koleksi, makanan, dan minuman. Selain itu, Elevenia juga menyediakan promosi dan e-kupon.

Beberapa marketplace di atas, tentu akan membuat dan membantu perkembangan belanja modern di tanah air, dan sangat membantu pertumbuhan pelaku usaha yang umumnya ingin memasarkan berbagai produknya ke dalam pasar yang lebih luas, secara praktis, hemat dan efisien dalam upaya mendapatkan pelanggan (Soekiman, Baktiono and Artaya, 2018). Kegiatan promosi dibentuk untuk menstimulasi terjadinya kesadaran, ketertarikan, dan akan berakhir dengan pembelian suatu produk (Afifah, Najamuddin and Humaeira, 2019).

\section{Metode}

Kegiatan pengabdian kepada masyarakat di Desa Ciberem ini menggunakan beberapa metode yaitu : pengumpulan data dan pendekatan persuasif edukatif dengan metode ceramah dan diskusi (Rahmawati 2017). Adapun teknik yang digunakan untuk pengumpulan data dalam penelitian ini adalah teknik observasi, wawancara, dan dokumentasi (sugiono 2016). Dilanjutkan dengan ceramah, diskusi dan penerapan / mempraktekan langsung hasil dari pelatihan. Berikut adalah tahapan tahapan yang dilakukan dalam kegiatan pengabdian masyarakat di desa ciberem:

1. Survay tempat pelaksanaan; 
2. Pengumpulan data;

3. konfirmasi dengan ketua paguyuban tanaman hias di desa ciberem;

4. pembuatan materi tentang media promosi online menggunakan market place;

5. penyampaian materi dengan metode ceramah dan diskusi;

6. pengenalan market place yang terkenal di indonesia;

7. mempraktekan tentang pembuatan akun market place;

Berdasarkan survay dan hasil wawancara ke pewakilan paguyuban tanaman hias desa ciberem dengan adanya penutupuan diberbagai tempat wisata khususnya di daerah banyumas, sangat mempengaruhi omset penjualan mereka. Sehingga karena ini kami bersepakat untuk mengadakan pelatihan dengan tema "pelatihan penggunaan marketplace sebagai media pemasaran online di paguyuban tanaman hias desa ciberem untuk memperluas pemasaran di era pandemi"dengan harapan nantinya penjualan yang tadinya hanya ada di lingkup area banyumas dapat meluas ke berbagai penjuru di seluruh indonesia, sehingga omset penjualanpun dapat meningkat.

\section{Hasil dan Pembahasan}

Kegiatan pengabdian di lakukan pada hari sabtu, 10 november 2020 dengan peserta sebanyak 12 orang. Sesi pelatihan penggunaan market place dimulai dengan pengenalan tentang market place yang ada di indonesia seperti : tokpedia, lazada, bukalapak, blibli, shope dan masih banyak aplikasi lain yang merupakan penyedia jasa penjualan online. Pembahasan selanjutnya membahas tentang fitur - fitur yang ada pada masing masing aplikasi market place yang bisa dimanafaatkan sebagai media penjualan online, serta pemanfaatan fitur ads (iklan) yang mana dapat membuat produk kita bisa tampil di halaman depan. Dilanjutkan dengan mencoba mengaplikasikan langsung cara berjualan di marketplace. Dalam hal ini kita mencoba melalui salah satu aplikasi marketplace tokopedia.

\section{Simpulan dan Rekomendasi}

Melalui kegiatan pengabdian kepada masyarakat dengan judul "Pelatihan Penggunaan Market Place sebagai Media Pemasaran Online di Paguyuban Tanaman Hias Desa Ciberem untuk Memperluas Pemasaran di Era Pandemi” dapat disimpulkan bahwa secara keseluruhan kegiatan pengabdian berjalan dengan baik.

Market Place dapat di optimalkan penggunaannya sebagai media pemasaran secara digital dengan memanfaatkan berbagai fitur yang ada. Kegiatan pengabdian yang telah dilaksanakan diharapkan dapat memberikan pengetahuan dan informasi mengenai pemasaran produk melalui market place serta memotivasi para peserta untuk mengoptimalkan penggunaan market place sebagai media promosi online. Selain itu, kegiatan pengabdian diharapkan mampu meningkatkan keterampilan peserta dalam menuangkan gagasan dalam bentuk tulisan yang dikombinasikan dengan foto maupun video dalam promosi di market place.

Dari kegiatan pengabdian yang telah dilaksanakan, peserta berharap agar kegiatan yang sejenis dapat dilakukan secara bekelanjutan seperti misalnya pemanfaatan sosial media sebagai media promosi, pelatihan tentang teknik foto untuk bisnis, branding produk, dan pelatihan pelatihan marketing sejenisnya yang dapat membantu masyarakat khususnya paguyuban tanaman hias di desa ciberem dapat memperluas pemasaran sehingga omset dapat meningkat. 


\section{Kesimpulan}

Melalui kegiatan pengabdian kepada masyarakat dengan judul "Pelatihan Penggunaan Market Place sebagai Media Pemasaran Online di Paguyuban Tanaman Hias Desa Ciberem untuk Memperluas Pemasaran di Era Pandemi" dapat disimpulkan bahwa secara keseluruhan kegiatan pengabdian berjalan dengan baik. Market Place dapat di optimalkan penggunaannya sebagai media pemasaran secara digital dengan memanfaatkan berbagai fitur yang ada. Kegiatan pengabdian yang telah dilaksanakan diharapkan dapat memberikan pengetahuan dan informasi mengenai pemasaran produk melalui market place serta memotivasi para peserta untuk mengoptimalkan penggunaan market place sebagai media promosi online. Selain itu, kegiatan pengabdian diharapkan mampu meningkatkan keterampilan peserta dalam menuangkan gagasan dalam bentuk tulisan yang dikombinasikan dengan foto maupun video dalam promosi di market place.

\section{Daftar Pustaka}

Afifah, L., Najamuddin, M. and Humaeira, B. (2019) 'EFEKTIVITAS MEDIA PROMOSI PADA PRODUK SANDWICH GORENG MEREK ROYAL SANDWICH’, AGRIBUSINESS JOURNAL. doi: 10.15408/aj.v13i1.11868.

Artaya, P. and Purworusmiardi, T. (2019) 'Efektifitas Marketplace Dalam Meningkatkan Konsentrasi', (April). doi: 10.13140/RG.2.2.10157.95206.

Hendriadi, A. A., Sari, B. N. and Padilah, T. N. (2019) 'Pelatihan Digital Marketing Usaha Mikro, Kecil dan Menengah (UMKM) di Kabupaten Karawang', J-Dinamika, 4(2), pp. 120 125. doi: 10.25047/j-dinamika.v4i2.1133.

Nathasya. apa itu marketplace. 2018. https://www.dewaweb.com/blog/apa-itu-marketplace/.

Rahmawati, A. "Education Method of Lectures and Discussionstoward Health Cadre Ability in Early." Jurnal Ilmiah Pemenang, 2017.

Soekiman, J. S., Baktiono, A. and Artaya, I. P. (2018) 'Optimization of governance model of post-food harest and distribution in msme centers in 5 subdistricts in sidoarjo regency', Journal of Economics, Business \& Accountancy Ventura, 20(3), pp. 295-308. doi: 10.14414/jebav.v20i3.1089.

Artaya, Putu. "Efektifitas Marketplace Dalam Meningkatkan Konsentrasi." 2019.

Sugiono. Metode Penelitian Pendidikan: Pendekatan Kuantitatif, Kualitatif, dan R\&D.

Bandung: Alfabeta, 2016.

Xohop, Admin. Apa Itu Marketplace. 2017. http://www.xohop.com/blog/detail/123/apa-itumarketplace. 